JOURNAL OF APPLIED SMART ELECTRICAL
NETWORK AND SYSTEMS (JASENS)
ISAS

\title{
Rancang Bangun Mesin Air Press Assy Otomatis Berbasis PLC
}

\author{
Tri Hannanto Saputra ${ }^{1}$, Cornelius Hendriarto ${ }^{2}$ \\ ${ }^{1}$ Program Studi Teknik Perancangan Mekanik dan Mesin, Politeknik ATMI Surakarta \\ 2Program Studi Teknik Perancangan Mekanik dan Mesin, Politeknik ATMI Surakarta \\ 1hannanto.saputra@atmi.ac.id*,20ornelius.hendriarto@atmi.ac.id
}

\begin{abstract}
Motor vehicle light boxes require a lamp holder installation process. This study aims to automate the process of installing a lamp holder into a motorized vehicle light box through the design of an air press machine. The machine has 5 (five) process stages, namely installing the lamp box on the jig, installing the lamp holder, pressing the lamp holder, installing the lamp on the holder, taking the lamp box from the jig. The product is pressed automatically through a cylinder press mechanism. Based on the test results, it is known that the machine takes an average of 9 (nine) seconds to install the lamp and lamp holder into the light box. The result of this machine is that the time produced is 3 (three) seconds faster than the previous machine, which takes an average of 12 (twelve) seconds. The use of machines has the potential to increase productivity and workforce efficiency. The machine in this research can be developed to increase the efficiency of the assembly process.
\end{abstract}

Keywords: Press Machine, Vehicle Light, PLC, Cylinder, Automatic

\begin{abstract}
Abstrak
Box lampu kendaraan bermotor membutuhkan proses pemasangan dudukan (holder) lampu. Penelitian ini bertujuan melakukan otomatisasi proses pemasangan dudukan (holder) lampu kedalam box lampu kendaraan bermotor melalui rancang bangun mesin air press assy. Mesin memiliki 5 (lima) tahapan proses yaitu pemasangan bok lampu pada jig, pemasangan holder lampu, pengepresan holder lampu, pemasangan lampu pada holder, pengambilan bok lampu dari jig. Produk dipress secara otomatis melalui mekanisme silinder press. Berdasarkan hasil uji coba, diketahui bahwa mesin memerlukan waktu rata-rata sebesar 9 (sembilan) detik untuk memasang lampu dan holder lampu kedalam box lampu. Hasil dari mesin ini yaitu waktu yang dihasilkan 3 (tiga) detik lebih cepat dibandingkan mesin sebelumnya, yang memerlukan waktu rata-rata sebesar 12 (dua belas) detik. Penggunaan mesin berpotensi meningkatkan produktivitas dan efisiensi tenaga kerja. Mesin pada penelitian ini dapat dikembangkan untuk meningkatkan efisiensi proses assembly.
\end{abstract}

Kata kunci: Mesin Press, Lampu Kendaraan, PLC, Silinder, Otomatis

Diterima Redaksi : 15-12-2020 | Selesai Revisi : 27-12-2020 | Diterbitkan Online : 31-12-2020

\section{Pendahuluan}

Kendaraan bermotor memiliki beberapa komponen. Salah satu komponen pada kendaraan bermotor yaitu box lampu kendaraan. Box lampu kendaraan memiliki 3 (tiga) bagian yaitu box lampu, holder lampu dan lampu kendaraaan. Lampu adalah komponen untuk memberikan cahaya atau menerangi jalan. Inovasi proses manufaktur perlu dilakukan untuk meningkatkan efisiensi proses produksi sebelumnya. Inovasi proses manufaktur tidak harus dilakukan secara radikal, namun dapat dilakukan dengan metode inovasi lokal, yaitu dengan menerapkan solusi yang telah ada di dunia industri namun relatif masih baru bagi perusahaan [1].

Perancangan mesin press sebelumnya dilakukan [2] bermotor melalui rancang bangun mesin air press assy. dengan menggunakan elektro hidrolik. [3] menggunakan Penelitian akan membuat rancang bangun pengontrolan hidrolik untuk Robotic Lifting Device. [4] melakukan sistem pengepresan peralatan listrik yang bekerja secara optimization hot stamping dengan menggunakan elektro otomatis menggunakan PLC (Programmable Logic pneumatik. Penelitian lain juga telah dilakukan dengan Controller). PLC akan diprogram sesuai dengan menggunakan PLC. [5] menggunakan PLC sebagai kontrol sistem hidrolik, sedangkan [6] menggunakan PLC sebagai kontrol pneumatic untuk Punching Machine. Namun design punching machine yang dibuat tidak memungkinkan operator untuk melakukan pengaturan waktu penekanan. Mesin Press sebelumnya masih menggunakan kontrol konvensional. Operator tidak dapat mengatur waktu penekanan silinder.

Berdasarkan penelitian dan mesin sebelumnya, maka dilakukan penelitian mesin air press assy yang menggunakan kontrol PLC. Penelitian ini bertujuan untuk melakukan otomatisasi proses pemasangan dudukan (holder) lampu kedalam box lampu kendaraan bermotor melalui rancang bangun mesin air press assy. 
kebutuhan proses. Sistem kendali yang dikontrol oleh PLC ini adalah system kendali yang dilengkapi dengan beberapa sensor untuk bekerja secara otomatis, juga dilengkapi dengan box panel kontrol yang berisi komponen-komponen dari system control tersebut [7][8][9].

Mesin dirancang untuk meningkatkan efisiensi mesin produksi sebelumnya. Seperti yang disampaikan oleh [10][11], faktor yang penting dalam efisiensi jalur produksi adalah pemanfaatan tenaga kerja dan efisiensi mesin produksi. Perancangan mesin otomatis ini merupakan usaha untuk meningkatkan efisiensi mesin produksi. Inovasi yang dilakukan dalam mesin press ini yaitu mesin dikontrol dengan menggunakan PLC, sehingga harapannya proses eksekusi aktuator dapat lebih cepat. Selain itu inovasi lain yang dilakukan yaitu waktu penekanan dapat diatur oleh operator.

\section{Metode Penelitian}

Metode yang digunakan pada penelitian ini mengadopsi metode generic product development process yang dikembangkan oleh [12]. Penelitian ini menggunakan lima dari enam tahap generic product development yaitu tahap perencanaan, tahap pengembangan konsep, tahap perancangan tingkat sistem, tahap perancangan detail, dan tahap pengujian.

Tahap perencanaan terdiri dari identifikasi peluang, penyusunan tujuan, penentuan batasan, serta penentuan platform teknologi mesin yang akan digunakan. Tahap ini secara garis besar telah dijelaskan pada sub judul pendahuluan. Tahap pengembangan konsep adalah tahap untuk menentukan konsep mesin meliputi bentuk, fungsi, fitur dan solusi teknologi yang diperlukan. Tahap perancangan tingkat sistem adalah tahap untuk menghasilkan rancangan arsitektur mesin, sub sistem penyusun, dan diagram aliran proses. Tahap perancangan detail terdiri dari penentuan spesifikasi teknis komponen-komponen yang diperlukan serta rancangan panel kendali dan kelistrikan. Tahap pengujian adalah tahap untuk menguji rancangan mesin meliputi fungsi, performa kecepatan, dan kualitas hasil proses mesin. Kualitas hasil pencucian pada penelitian ini diperiksa secara kualitatif dan divalidasi oleh operator yang telah berpengalaman. Blok diagram system keseluruhan mesin adalah sebagai berikut :

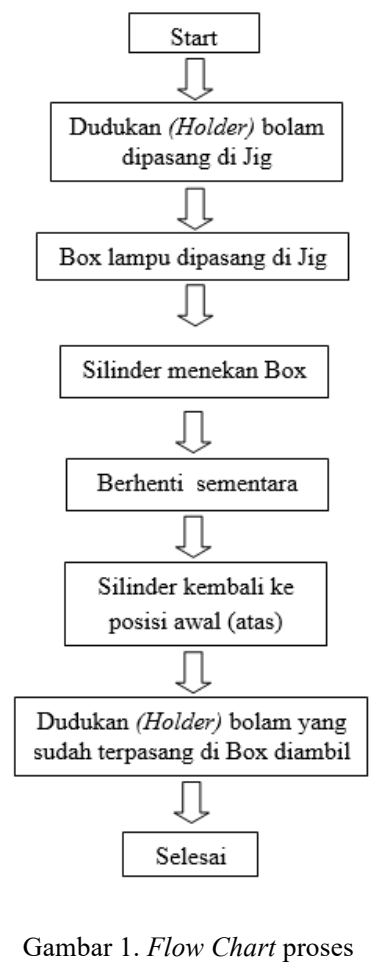

\section{Hasil dan Pembahasan}

Pembahasan dan hasil analisa penelitian adalah sebagai berikut

\subsection{Alat dan Bahan}

a. Penepat (Jig) untuk memasang Dudukan (Holder) dan Box lampu

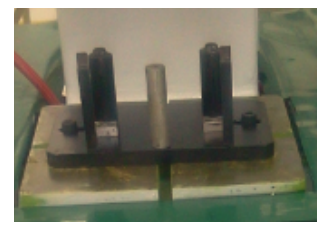

Gambar 2. Jig

b. Sensor Keamanan

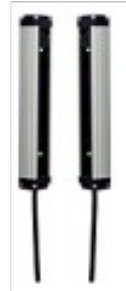

Gambar 3. Area Sensor BW $40-10$

Spesifikasi:

Power Supply : $24 \mathrm{VDC}$ 
c. Silinder Press

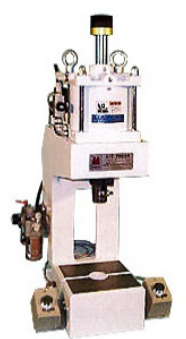

Gambar 4. Silinder Maruni MSP 2000 DA F1

Spesifikasi:

$\begin{array}{ll}\text { Tekanan } & : 4 \mathrm{Bar} \\ \text { Tegangan Selenoid Valve } & : 220 \mathrm{VAC} \\ \text { Stroke (Pergerakan Naik-turun) } & : 100 \mathrm{~mm} \\ \text { Kekuatan penekanan } & : 5 \mathrm{~kg} / \mathrm{cm}^{2}\end{array}$

Silinder telah dilengkapi sensor berupa limit switch up dan down. Sensor berfungsi untuk membatasi pergerakan naik dan turun silinder.

\section{c. Operation control}

Operation control terdiri dari Switch dan Push Button yang terdiri dari Switch Power, Switch Manual Auto, Switch Up Down, Push Button Emergency, Push Button Reset, Push Button Start dan Push Button Origin.

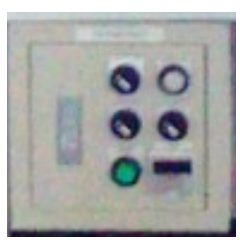

Gambar 5. Operation Control

d. Modul Timer

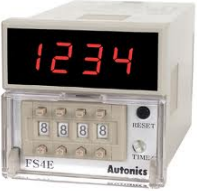

Gambar 6. Modul Timer Autonics FS4E

Spesifikasi:

Power Supply : :24VDC

Kontak $: 2 \mathrm{NO}, 2 \mathrm{NC}$

d. Programmbale Logic Controller (PLC)

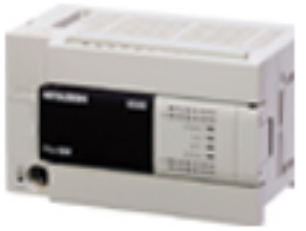

Gambar 7. PLC Mitsubishi FX3U-32MR-ES/UL
Spesifikasi:

$\begin{array}{ll}\text { Power Supply } & : 220 \mathrm{VAC} \\ \text { Jumlah Input } & : 16 \mathrm{pcs} \\ \text { Jumlah Output } & : 16 \mathrm{pcs}\end{array}$

3.2. Gambar Mesin

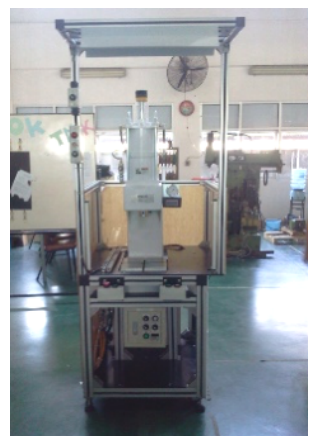

(a)

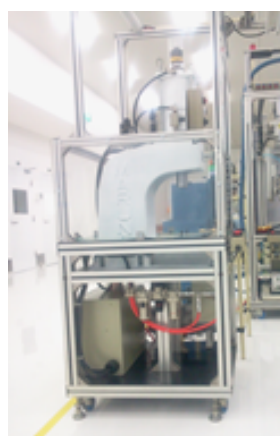

(b)
Gambar 8. Mesin (a) tampak depan (b) tampak samping

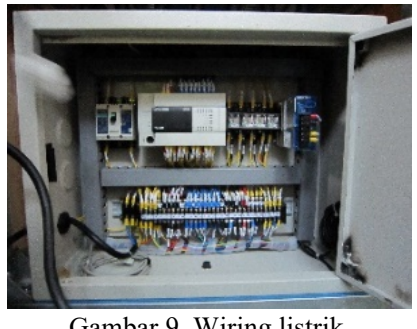

Gambar 9. Wiring listrik

\subsection{Cara Kerja Mesin}

Mesin Press berfungsi untuk memasang holder lampu ke dalam box lampu. Proses kerja mesin diatur oleh Programmbale Logic Controller (PLC). Fungsi dari PLC yaitu mengontrol proses sekuensial mesin melalui modul I/O berdasarkan program yang telah dibuat. PLC akan mengaktifkan output yang berupa solenoid up, solenoid down dan lampu setelah mendapatkan input dari operation control, sensor dan timer. Modul Timer digunakan agar operator dapat mengatur waktu penekanan silinder secara manual. Sehingga waktu penekanan tidak menggunakan timer internal PLC. Sensor keamanan menggunakan area sensor. Sensor keamanan berfungsi untuk melindungi operator, jika ada bagian tubuh operator yang masuk didalam area kerja ketika mesin aktif, maka PLC akan secara otomatis menghentikan proses. 
3.4 Analisa Daya

Tabel 1. Data Daya Mesin

\begin{tabular}{llrrr}
\hline No & Penggerak & $\begin{array}{c}\text { Tegangan } \\
(\mathrm{V})\end{array}$ & $\begin{array}{c}\text { Arus } \\
(\mathrm{I})\end{array}$ & \multicolumn{2}{c}{$\begin{array}{c}\text { Daya } \\
(\mathrm{W})\end{array}$} \\
\hline 1 & PLC & 220 & 0,02 & 5 \\
2 & Selenoid Up & 220 & 0,02 & 5 \\
3 & Selenoid Down & 220 & 0,02 & 5 \\
4 & Lampu & 220 & 0,18 & 40 \\
5 & Modul Timer & 24 & 0,04 & 1 \\
6 & Modul Counter & 24 & 0,04 & 1 \\
\hline
\end{tabular}

Berdasarkan data Tabel 1. dapat dilihat bahwa total daya mesin yaitu 57 watt.

\subsection{Hasil Percobaan}

Hasil Mesin Press dikatakan baik (Good) atau memiliki ketepatan, jika jarak antara box lampu dengan holder lampu (x) memiliki selisih $<0,2 \mathrm{~mm}$. Berikut tabel hasil percobaan yan telah dilakukan.

a. Uji coba kekuatan Silinder

Tabel 2. Kekuatan Penekanan

\begin{tabular}{ccccc}
\hline No & $\begin{array}{c}\text { Kekuatan } \\
\text { Penekanan }\end{array}$ & $\begin{array}{c}\text { Tekanan } \\
\text { Angin }\end{array}$ & $\begin{array}{c}\mathrm{X} \\
(\mathrm{mm})\end{array}$ & Keterangan \\
\hline 1 & $1 \mathrm{~kg} / \mathrm{cm}^{2}$ & $4 \mathrm{bar}$ & 0,40 & $\mathrm{NG}$ \\
2 & $2 \mathrm{~kg} / \mathrm{cm}^{2}$ & $4 \mathrm{bar}$ & 0,35 & $\mathrm{NG}$ \\
3 & $3 \mathrm{~kg} / \mathrm{cm}^{2}$ & $4 \mathrm{bar}$ & 0,32 & $\mathrm{NG}$ \\
4 & $4 \mathrm{~kg} / \mathrm{cm}^{2}$ & $4 \mathrm{bar}$ & 0,25 & $\mathrm{NG}$ \\
5 & $5 \mathrm{~kg} / \mathrm{cm}^{2}$ & $4 \mathrm{bar}$ & 0,15 & $\mathrm{G}$ \\
\hline \multicolumn{4}{l}{ Keterangan $\cdot G=$ Good $N G=N o t$ Good }
\end{tabular}

Keterangan : $G=$ Good, $N G=$ Not Good

Berdasarkan Tabel 2. dapat disimpulkan bahwa holder dapat terpasang di box secara sempurna pada kekuatan [4] penekanan $5 \mathrm{~kg} / \mathrm{cm}^{2}$ dan tekanan angin sebesar 4 bar.

b. Uji coba waktu penekanan

Tabel 3. Waktu Penekanan

\begin{tabular}{rrrcc}
\hline No & $\begin{array}{c}\text { Waktu } \\
\text { Penekanan }\end{array}$ & $\begin{array}{c}\text { Tekanan } \\
\text { Angin }\end{array}$ & $\begin{array}{c}\mathrm{X} \\
(\mathrm{mm})\end{array}$ & Keterangan \\
\hline 1 & $1 \mathrm{dt}$ & $4 \mathrm{bar}$ & 0,42 & $\mathrm{NG}$ \\
2 & $1,5 \mathrm{dt}$ & $4 \mathrm{bar}$ & 0,36 & $\mathrm{NG}$ \\
3 & $1,75 \mathrm{dt}$ & $4 \mathrm{bar}$ & 0,30 & $\mathrm{NG}$ \\
4 & $2 \mathrm{dt}$ & $4 \mathrm{bar}$ & 0,25 & $\mathrm{NG}$ \\
5 & $3 \mathrm{dt}$ & $4 \mathrm{bar}$ & 0,10 & $\mathrm{G}$ \\
\hline
\end{tabular}

Keterangan : $G=$ Good, $N G=$ Not Good

Berdasarkan Tabel 3. dapat disimpulkan bahwa holder dapat terpasang di box secara sempurna jika waktu penekanan sebesar $3 \mathrm{dt}$ dan tekanan angin sebesar 4 bar.

\section{Kesimpulan}

Penelitian ini berhasil mengembangkan mesin press otomatis untuk melakukan pemasangan holder lampu kedalam box lampu kendaraan bermotor secara otomatis. Mesin press yang dikembangkan bertujuan meningkatkan esiensi proses produksi. Mesin dirancang menggunakan metode generic product development process. Inovasi yang dilakukan dalam mesin press ini yaitu mesin dikontrol dengan menggunakan PLC, sehingga harapannya proses eksekusi aktuator dapat lebih cepat. Selain itu inovasi lain yang dilakukan yaitu waktu penekanan dapat diatur oleh operator. Hasil uji coba menunjukkan proses pengepresan atau waktu total lebih cepat yaitu $9 \mathrm{dt}$, jika dibandingkan dengan proses total sebelumnya yaitu $12 \mathrm{dt}$. Jadi dapat disimpulkan bahwa dengan adanya penggunaan PLC, terjadi percepatan proses selama $3 \mathrm{dt}$. Hasil tersebut berpotensi memberikan keuntungan bagi perusahaan. Efisiensi keseluruhan proses permesinan masih dapat dikembangkan kembali. Penelitian lanjutan masih diperlukan untuk meningkatkan efisiensi mesin, berupa mekanisme pemasangan lampu secara otomatis.

\section{Daftar Rujukan}

[1] Yamamoto, Y., Bellgran, M. Four types of manufacturing process innovation and their managerial concerns. Procedia CIRP. 2013; 7: 479-484.

[2] Olukorede Tijani Adenuga and Khumbulani Mpofu.(2014) "Control system for electro-hydraulic synchronization on RBPT." Procedia CIRP 17: 835 - 840

[3] A.O.M.Adeoye,A.A.Aderoba and B.I. Oladapo.(2017) "Simulated Design of a Flow Control Valve for Stroke Speed Adjustment of Hydraulic Power of Robotic Lifting Device." Procedia Engineering 173:1499-1506

4] Bankole I. Oladapo, Vincent A. Balogun, Adeyinka O.M. Adeoye, Ige E. Olubunmi and Samuel O. Afolabi.(2017) "Experimental analysis of electro-pneumatic optimization of hot stamping machine control systems with on-delay timer." Journal of Applied Research and Technology 15: 356-364

[5] WANG Hong. (2011) "Design of PLC-based Hydraulic System for Workpiece Turnover." Procedia Engineering 15:122-126.

[6] Sudeep Kelaginamane, Sridhar D. R. "PLC Based Pneumatic Punching Machine," Journal of Mechanical Engineering and Automation, 2015, Vol 5(3B), pp. 76-80.

[7] S. Primadewi Riyani, Darpono Rony, "Simulasi Sistem Kontrol Buka Tutup Pintu Gerbang Berbasis Plc Pada Trainer Sebagai Media Pembelajaran Di Politeknik Harapan Bersama," J. Power Elektron. J. Orang Elektro, vol. 6, no. 2, p. 7, 2017.

[8] A. Bakhtiar, "Panduan Dasar Outseal PLC", p. 91, 2019.

[9] SRI SUPATMI, "Pengaruh Sensor Ldr Terhadap Pengontrolan Lampu", Maj. Ilm. UNIKOM, vol. 8, no. 2, pp. 175-180, 2010.

[10] Subramaniam, S. K. A. L., Husin, S. H. B., Yusop, Y. B., \& Hamidon, A. H. B. (2008). Machine efficiency and man power utilization on production lines. In WSEAS International Conference. Proceedings. Mathematics and Computers in Science and Engineering (No.7) World Scientific and Engineering Academy and Society.

[11]Bruce J. Black, "Workshop Processes, Practices and Materials," Routledge, 5th edition, 2015.

[12]Eppinger, S., Ulrich, K. Product design and development. McGraw-Hill Higher Education. 2015: 15 